\title{
Long-lasting alterations in adipose tissue density and adiponectin production in people living with HIV after thymidine analogues exposure
}

Marco Gelpi ${ }^{1}$, Andreas Dehlbæk Knudsen ${ }^{1}$, Karoline Brostrup Larsen ${ }^{1}$, Amanda Mocroft ${ }^{2}$, Anne-Mette Lebech', Birgitte Lindegaard ${ }^{3,4}$, Jens Lundgren ${ }^{1,5}$, Klaus Fuglsang Kofoed ${ }^{6,7}$, Susanne Dam Nielsen ${ }^{1 *}$ (D) and on behalf of the Copenhagen Comorbidity in HIV Infection (COCOMO) Study

\begin{abstract}
Background: Thymidine analogues (TA) and didanosine ( $\mathrm{ddl}$ ) are associated with long-lasting adipose tissue redistribution. Adiponectin is a widely used marker of adipocyte activity, and adipose tissue density assessed by CTscan is associated with adipocyte size and function. We hypothesized that prior exposure to TA and ddl was associated with long-lasting adipose tissue dysfunction in people living with HIV (PLWH). Thus, we tested possible associations between markers of adipose tissue dysfunction (adipose tissue density and adiponectin) and prior exposure to TA and/or ddl, years after treatment discontinuation.

Methods: Eight hundred forty-eight PLWH from the COCOMO study were included and stratified according to prior exposure to TA and/or ddl (with, $n=451$; without $n=397$ ). Visceral (VAT) and subcutaneous (SAT) adipose tissue area and density were determined by single slice abdominal CT-scan at lumbar 4th level. Venous blood was collected and analyzed for adiponectin. Multivariable linear and logistic regression analyses were used to test our hypotheses. Multivariable models were adjusted for age, sex, smoking, origin, physical activity, BMI, and adipose tissue area (VAT or SAT area, accordingly to the outcome).

Results: prior exposure to TA and/or ddl was associated with excess risk of low VAT (adjusted OR (aOR) 1.74 [1.14; 2.67]) and SAT density (aOR $1.74[1.18 ; 2.58])$, for a given VAT and SAT area, respectively. No association between VAT and SAT density with time since TA and/or ddl discontinuation was found. $10 \mathrm{HU}$ increase in VAT density was associated with higher adiponectin plasma level and this association was not modified by prior exposure to TA and/or ddl. Prior exposure to TA and/or ddl was associated with 9\% lower [-17;-2] plasma adiponectin levels and with excess risk of low adiponectin (aOR 1.74 [1.10; 2.76]).
\end{abstract}

Conclusions: We described low adipose tissue density and impaired adiponectin production to be associated with prior exposure to TA and/or ddl even years after treatment discontinuation and independently of adipose tissue area. These findings suggest that prior TA and ddl exposure may have long-lasting detrimental effects on adipose tissue function and, consequently, on cardiometabolic health in PLWH.

Keywords: HIV, Visceral fat, Adipose tissue function, Adiponectin, Adipocytes

\footnotetext{
* Correspondence: sdn@dadlnet.dk

'Viro-immunology Research Unit, Department of Infectious Diseases 8632,

Rigshospitalet - University of Copenhagen, Blegdamsvej 9B, DK-2100

Copenhagen $\varnothing$, Denmark

Full list of author information is available at the end of the article
}

(c) The Author(s). 2019 Open Access This article is distributed under the terms of the Creative Commons Attribution 4.0 International License (http://creativecommons.org/licenses/by/4.0/), which permits unrestricted use, distribution, and

reproduction in any medium, provided you give appropriate credit to the original author(s) and the source, provide a link to the Creative Commons license, and indicate if changes were made. The Creative Commons Public Domain Dedication waiver (http://creativecommons.org/publicdomain/zero/1.0/) applies to the data made available in this article, unless otherwise stated. 


\section{Introduction}

Thymidine analogues (TA) and didanosine (ddI) have known deleterious effect on adipose tissue metabolism [1]. Previous results from our group suggested that prior use of TA and ddI in people living with HIV (PLWH) is associated with alterations in body fat distribution, particularly loss of subcutaneous (SAT) and accumulation of visceral adipose tissue (VAT) [1], even years after treatment discontinuation. This phenotype is known to be associated with increased of cardiometabolic risk.

Unfavorable changes in adipose tissue function and quality accompanies ectopic fat deposition and are strongly associated with increased incidence of cardiovascular diseases in uninfected individuals [2]. Recently, the association between computed tomography-measured adipose tissue density (measured in Hounsfield Units (HU)) and both adipocytes size and function has been described [3-6]. Low adipose tissue density has been suggested to indicate adipocyte hypertrophy and is associated with reduced secretory capabilities, both of which are considered hallmarks of adipose tissue dysfunction and increased cardiovascular risk [3, 4, 7, 8].

While it was previously only considered an energy storage, adipose tissue has drawn increasing attention as endocrine organ and as a fundamental crossway in inflammation control [9]. Alterations in plasma levels of adipokines follows adipose tissue dysfunction, and are associated with increased cardiovascular risk [3].

Our aim was to investigate if alterations in fat distributions found in PLWH with prior exposure to TA and/or ddI are accompanied by long-lasting markers of adipose tissue dysfunction even years after treatment discontinuation. Previous studies investigating adipose tissue quality in PLWH have relied on biopsy and invasive procedures and included a small number of participants. In the present study, we tested the hypotheses that: i) for a given VAT and SAT area, prior use of TA and/or ddI is associated with low VAT and SAT density, respectively; ii) VAT area and density are associated with adiponectin plasma levels and these associations are modified by prior exposure to TA and/or ddI; iii) for a given VAT area, prior use of TA and/or ddI is associated with excess risk of low adiponectin.

\section{Methods}

The Copenhagen comorbidity in HIV infection (COCOMO) study is a longitudinal study with the aim of assessing the burden of non-AIDS comorbities in PLWH. Of the 1099 PLWH enrolled in the COCOMO study, 848 PLWH with a CT-scan were included. Procedures for recruitment and data collection have been described in detail elsewhere [10].
Ethical approval was obtained by the Ethics Committee (H-15017350). Written informed consent was obtained from all participants.

\section{Clinical assessments}

Structured questionnaires were used to collect information about demographics, physical activity, and smoking. Data regarding HIV infection were obtained from review of medical charts [10].

All physical examinations were performed by clinic staff as previously described [10].

\section{Outcome definitions}

Low adiponectin was defined as having adiponectin plasma levels in the lowest quartile. Similarly, low VAT and SAT density were defined as having VAT and SAT density, respectively, in the lowest quartile.

\section{Blood samples}

Non-fasting venous blood was collected and analyzed for adiponectin at Herlev Hospital, Copenhagen [10].

\section{CT-scan measurement}

CT imaging was performed using 320-multidetector scanner (Aquilion One ViSION Edition, Canon, Japan) in a single rotation $(275 \mathrm{~ms})$. Field of view (FOV) was 500, tube voltage was $120 \mathrm{kVp}$ and current was $210 \mathrm{~mA}$ (independent of BMI). For measurement of visceral and subcutaneous adipose tissue, an $8 \mathrm{~mm}$ section $(2 \times 4.0 \mathrm{~mm})$ was reconstructed centered at the level of the 4th lumbar vertebra. Trained personnel used commercially available CT software (Fat Measurement, Aquilion ONE; Canon, Japan) to measure the cross-sectional area of adipose tissue defined as voxels with attenuation values in the range of -150 to -70 Hounsfield units. From within a manually adjusted region of interest delineated by the muscular compartments, VAT area was automatically calculated. SAT was defined as adipose tissue superficial to the abdominal and paraspinal muscles. Intraintestinal and intramuscular adipose tissues were manually excluded. Mean density for VAT and SAT, respectively, were calculated and reported, using four regions of interest within each fat depot. All measurements were performed by a single investigator blinded to stratification status. Intra-reader variability evaluation showed high intra-reader correlation (0.975 for VAT density, 0.973 for SAT density) and low mean intra-reader absolute difference (1.01, SD 0.77 for VAT density; 1.02, SD 0.99 for SAT density).

\section{Statistical analysis}

Continuous variables were reported as median and interquantile range [IQR] and categorical variables as frequency and percentage (\%). Different groups were compared with t-tests or Mann Whitney $U$ test for continuous data with 
normal or non-normal distribution, respectively, and chi square/Fisher's tests for categorical data. In regression analyses, adiponectin levels were log-transformed.

Associations between prior exposure to TA and/or ddI and our outcomes were explored with linear or logistic regression models for continuous or binary outcomes, respectively. B coefficients or odds ratio, respectively, and $95 \%$ confidence intervals [CIs] were computed and reported after adjustment for a base model, which included age, sex, smoking, origin, physical activity, BMI, and fat area (VAT or SAT area, accordingly to the outcome) as covariates.

Associations between our outcomes and the cumulative period of exposure to and the cumulative time since discontinuation of TA and/or ddI were explored by adding these covariates into the base model. These analyses included only individuals with prior exposure to TA and/or ddI.

Possible interactions of exposure to TA and/or ddI with VAT area and density, respectively, were tested in multivariable linear analysis models with plasma adiponectin levels as dependent variable.

Sensitivity analyses considering only individuals $>40$ years of age were performed.

Due to log-transformation of plasma adiponectin levels, regression results regarding this outcome are reported as changes in percentage.

$P$-values $<0.05$ were considered statistically significant. Statistical analyses were performed using R 3.4.1 (R Foundation, Austria).

\section{Results}

\section{Demographics and HIV-specific characteristics}

Eight hundred forty-eight PLWH from the COCOMO study were included and 451 (53.1\%) had current or prior exposure to TA and/or ddI. Of those, 445 (98.6\%) had only prior exposure, and 6 (1.4\%) were still exposed. The mean cumulative exposure period to TA and/or ddI was $6.6(\mathrm{SD}, 4.2)$ years and mean time since discontinuation was 9.4 (SD, 2.7) years. Demographics and HIVspecific characteristics are depicted in Table 1.

\section{Visceral adipose tissue density}

PLWH with exposure to TA and/or ddI had lower VAT density than PLWH without $(-113.9$ [-115.7 - -109.7] vs. $-108.9 \mathrm{HU}[-113.6--104.9], p$-value $<0.0001)$. This finding was reproduced also after stratification according to quartiles of VAT (Fig. 1). Prior exposure to TA and/or ddI was associated excess risk of low VAT density, both before (crude OR 2.76 [1.97; 3.87]) and after adjusting for confounders (aOR 1.74 [1.14; 2.67]) (Table 2). This association was found to be consistent in linear models (Additional file 1: Table S1). In PLWH with exposure to TA and/or ddI, no association between VAT density and either cumulative exposure period to or time since discontinuation of these treatments was found (Table 3).

\section{Subcutaneous adipose tissue density}

PLWH with exposure to TA and/or ddI had slightly lower SAT density $(-111.1 \mathrm{HU}[-113.7$ - -108.1$]$ vs. $-110.4 \mathrm{HU}$ [-112.7 - -106.0]; $p$-value 0.0002). This difference was more evident in linear regression models after adjusting for, among the others, SAT area (Additional file 1: Table S1). Accordingly, prior exposure to TA and/ddI was associated with excess risk of low SAT density, both before (crude OR $1.61[1.17 ; 2.22])$ and after adjusting for confounders (aOR $1.74[1.18 ; 2.58]$ ) (Table 2). This association was found to be consistent in linear models (Additional file 1: Table S1). Longer periods of cumulative exposure to TA and/or ddI were associated with lower SAT density (Table 3). No association between time since discontinuation of these treatments and SAT density was found (Table 3 ).

\section{Plasma adiponectin levels}

No difference in plasma adiponectin levels and in prevalence of low plasma adiponectin was found between PLWH with and without exposure (Table 1). After adjusting for confounders, prior exposure to TA and/or ddI was associated with $9 \%$ lower $[-17 ;-2]$ plasma adiponectin levels and with excess risk of low plasma adiponectin (aOR 1.74 [1.10; 2.76]). Borderline interaction between prior exposure to TA and/or ddI and VAT area on adiponectin plasma levels was found (p-interaction 0.063).

For a given VAT area, $10 \mathrm{HU}$ increase in VAT density was associated with $12 \%[1 ; 23]$ and $9 \%[-1 ; 22]$ higher plasma adiponectin levels in PLWH with and without exposure to TA and/or ddI, respectively, even though not statistically significant in the latter. The association between VAT density and adiponectin levels was not modified by prior exposure to TA and/or ddI (p-interaction 0.778). No association between SAT density and plasma adiponectin levels was found in the two groups.

\section{Sensitivity analyses}

All results were consistent when limiting the analyses to participants $>40$ years old.

\section{Discussion}

In the present study, prior exposure to TA and/or ddI was associated with excess risk of low adipose tissue density and low plasma adiponectin irrespective of fat quantity. These findings suggest that long-lasting alterations of fat distribution previously described in PLWH with prior exposure to TA and/or ddI [1] are accompanied by markers of adipose tissue dysfunction, even years after treatment discontinuation. 
Table 1 Study groups characteristics

\begin{tabular}{|c|c|c|c|}
\hline & Without exposure to TA and/or ddl $(n=397)$ & $\begin{array}{l}\text { With exposure to TA and/or } \\
\text { ddl }(n=451)\end{array}$ & $p$-value \\
\hline Age, mean (sd) & $46.1(10.5)$ & $55.2(10.2)$ & $<0.0001$ \\
\hline Sex, male, $n(\%)$ & $361(90.9)$ & $373(82.7)$ & 0.0006 \\
\hline Origin, n (\%) & & & 0.0497 \\
\hline Scandinavian & $274(70.3)$ & $343(76.9)$ & \\
\hline Other EU & 49 (12.6) & $44(9.9)$ & \\
\hline Middle East and Indian subcontinent & $13(3.3)$ & $5(1.1)$ & \\
\hline Other & $54(13.8)$ & $54(12.1)$ & \\
\hline BMI Categories, $n(\%)$ & & & 0.4838 \\
\hline$<18.5$ & $9(2.3)$ & $11(2.5)$ & \\
\hline $18.5-24.9$ & $211(53.3)$ & $232(51.8)$ & \\
\hline $25-29.9$ & $145(36.6)$ & $156(34.8)$ & \\
\hline 30 & $31(7.8)$ & $49(10.9)$ & \\
\hline Smoking status, $n(\%)$ & & & $<0.0001$ \\
\hline Never smoker & $162(41.8)$ & $136(30.8)$ & \\
\hline Current smoker & $119(30.7)$ & $112(25.3)$ & \\
\hline Former smoker & $107(27.6)$ & $194(43.9)$ & \\
\hline Physical activity, $n(\%)$ & & & 0.0709 \\
\hline Very inactive & $36(9.6)$ & $38(8.8)$ & \\
\hline Moderately inactive & $117(31.1)$ & $161(37.4)$ & \\
\hline Moderately active & $161(42.8)$ & $184(42.8)$ & \\
\hline Very active & $62(16.5)$ & $47(10.9)$ & \\
\hline Exposure to thymidine analogues and didanosine, $n(\%)$ & & & - \\
\hline Prior exposure & - & $445(98.6)$ & \\
\hline Current exposure & - & $6(1.4)$ & \\
\hline Mode of HIV transmission, $n(\%)$ & & & 0.0032 \\
\hline Heterosexual & $64(16.2)$ & $100(22.4)$ & \\
\hline IDU & $5(1.3)$ & $5(1.1)$ & \\
\hline MSM & $311(78.9)$ & $306(68.6)$ & \\
\hline Other & $14(3.6)$ & $35(7.8)$ & \\
\hline CD4 nadir < 200 cells, $n$ (\%) & $89(23.2)$ & $258(57.8)$ & $<0.0001$ \\
\hline Viral load < 50, n (\%) & $369(93.9)$ & $436(97.1)$ & 0.0357 \\
\hline Current cART, $n(\%)$ & $397(100.0)$ & $449(99.8)$ & 1 \\
\hline VAT area, $\mathrm{cm}^{2}$, median [iqr] & $62.3[32.2,109.2]$ & $106.5[55.8,166.5]$ & $<0.0001$ \\
\hline VAT density, HU, median [iqr] & $-108.9[-113.6,-104.9]$ & $-113.9[-115.7,-109.7]$ & $<0.0001$ \\
\hline SAT, $\mathrm{cm}^{2}$,median [iqr] & $137.9[88.6,198.2]$ & $126.2[81.2,177.2]$ & 0.0768 \\
\hline SAT density, HU, median [iqr] & $-110.4[-112.7,-106.0]$ & $-111.1[-113.7,-108.1]$ & 0.0002 \\
\hline Adiponectin, $\mu \mathrm{g} / \mathrm{ml}$, median [iqr] & $11.8[8.7,14.7]$ & $11.5[8.1,16.3]$ & 0.4822 \\
\hline Low adiponectin, $n$ (\%) & $74(23.3)$ & $105(28.8)$ & 0.1173 \\
\hline
\end{tabular}

Abbreviations: visceral adipose tissue, VAT; subcutaneous adipose tissue, SAT; body mass index, BMI; standard deviations, SD; intravenous drug use, IDU; male-tomale sex, MSM, combined antiretroviral therapy, cART thymidine nucleoside analog reverse-transcriptase inhibitors, TA; Hounsfield units, HU

TA analogues were among the first antiretroviral treatments introduced to face the HIV epidemic. While effective in helping to control viral replication, they were characterized by severe adverse effects on adipose tissue, whose reversibility is still a subject of debate $[1,11]$. While the current use of TA and ddI has declined worldwide, TA was one of the recommended initial antiretroviral treatments until 2005 [12] and any lasting 


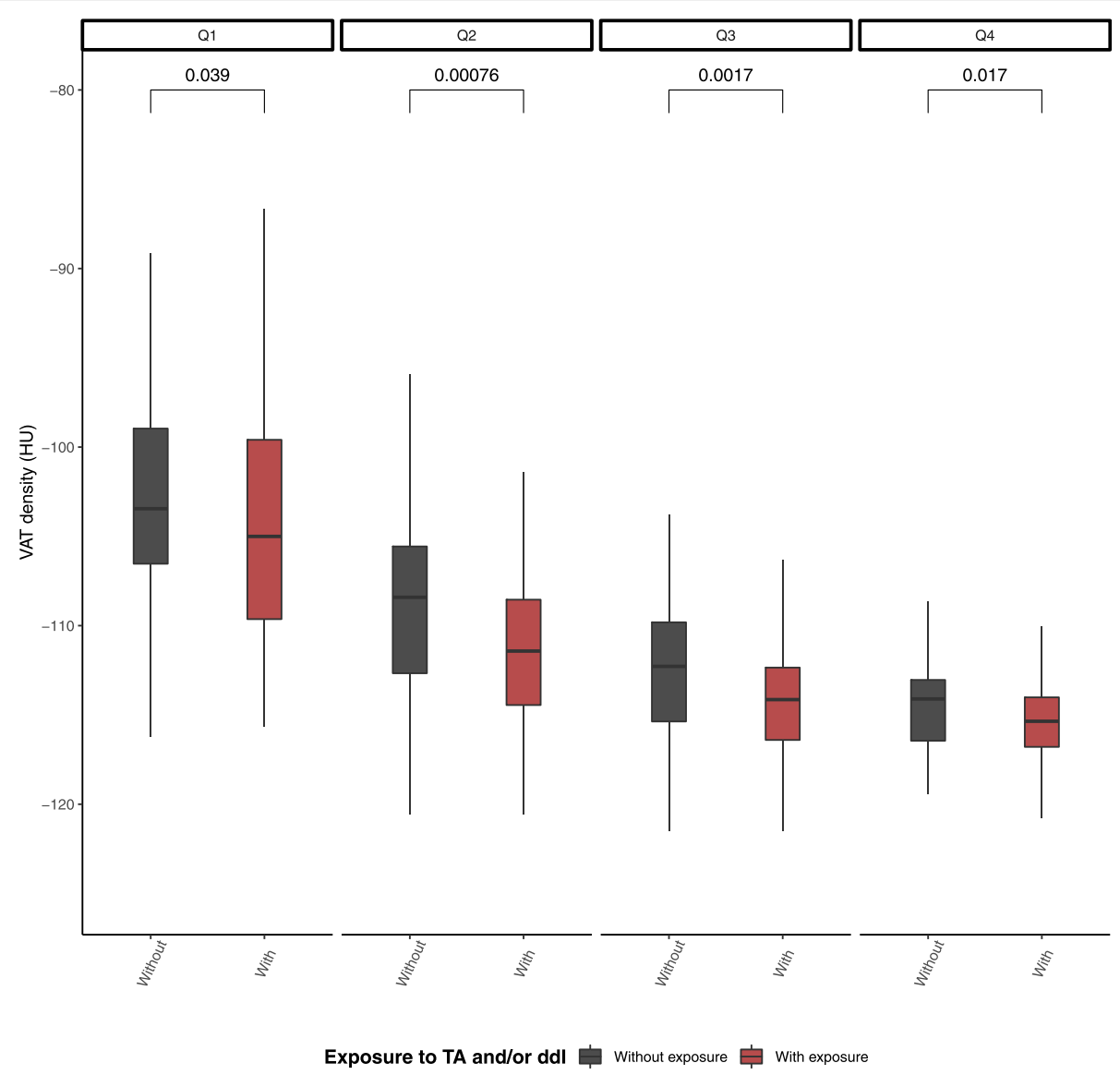

Fig. 1 Comparison of visceral adipose tissue density in people living with HIV with and without prior exposure to TA and/or ddl stratified in quartiles of VAT. Differences in VAT density between PLWH with and without exposure to TA and/or ddl after stratification of participants according to quartiles of VAT area. Abbreviations: people living with HIV, PLWH; thymidine nucleoside analog reverse-transcriptase inhibitors, TA; didanosine, ddl; visceral adipose tissue, VAT; Hounsfield unit, HU; quartiles 1-4, Q1-4

detrimental effects will continue to affect a large proportion of PLWH. Accordingly, increased risk of abdominal obesity and visceral adipose tissue accumulation has been recently described in PLWH, especially in those with prior exposure to TA and/or ddI [1, 13].

The accumulation of adipose tissue can be characterized by hyperplasia (increase in number of cells) or hypertrophy (increase in cell size) [7]. While the former is accompanied by well-preserved adipocyte function, adipocyte hypertrophy is associated with increased lipid content and decreased secretory function [7]. Adipocytes size is inversely associated with adipose tissue density, measured by CT-scan [3, 8, 14]. Previous studies described lower adipose tissue density to be associated with adverse cardiovascular risk in uninfected individuals $[2,3,5,8]$. In the present study, for a given VAT and SAT area, prior use of TA and/or ddI was associated with lower adipose tissue density. This finding may

Table 2 Association of prior exposure to TA and/or ddl with low VAT and SAT density

\begin{tabular}{|c|c|c|c|c|}
\hline & \multicolumn{2}{|c|}{ Low visceral adipose tissue density } & \multicolumn{2}{|c|}{ Low subcutaneous adipose tissue density } \\
\hline & Crude OR [95\% Cl] & Adjusted OR $[95 \% \mathrm{Cl}]^{*}$ & Crude OR $[95 \% \mathrm{Cl}]$ & Adjusted OR $[95 \% \mathrm{Cl}]^{* *}$ \\
\hline Prior exposure to TA and/or ddl & $2.76[1.97 ; 3.87]$ & $1.74[1.14 ; 2.67]$ & $1.61[1.17 ; 2.22]$ & $1.74[1.18 ; 2.58]$ \\
\hline Age, per 10 years & $1.78[1.53 ; 2.07]$ & $1.23[1.01 ; 1.50]$ & $1.23[1.07 ; 1.42]$ & $1.17[0.98 ; 1.40]$ \\
\hline Sex, male & $2.21[1.25 ; 3.90]$ & $1.73[0.84 ; 3.57]$ & $0.84[0.53 ; 1.31]$ & $2.90[1.57 ; 5.35]$ \\
\hline VAT area, per $50 \mathrm{~cm}^{2}$ increase & $2.18[1.91 ; 2.49]$ & $1.89[1.59 ; 2.25]$ & - & - \\
\hline SAT area, per $50 \mathrm{~cm}^{2}$ increase & - & - & $1.28[1.16 ; 1.42]$ & $2.00[1.64 ; 2.43]$ \\
\hline
\end{tabular}

Abbreviations: visceral adipose tissue, VAT; subcutaneous adipose tissue, SAT; thymidine nucleoside analog reverse-transcriptase inhibitors, TA; didanosine, ddl. Multivariable models were adjusted for: age, sex, origin, physical activity, BMI, smoking, VAT* (or SAT**) area, and prior exposure to TA and/or ddl 
Table 3 Association between cumulative periods of exposure to and time since discontinuation of TA and ddl with adipose tissue density

\begin{tabular}{|c|c|c|c|c|}
\hline & VAT density & $p$-value & SAT density & $p$-value \\
\hline & \multicolumn{2}{|l|}{ Adjusted $\beta^{*}[95 \% \mathrm{Cl}]$} & \multicolumn{2}{|l|}{ Adjusted $\beta^{* *}[95 \% \mathrm{Cl}]$} \\
\hline \multicolumn{5}{|c|}{ Cumulative time of exposure to TA and/or ddl } \\
\hline$<3.6$ years & Ref & & Ref & \\
\hline $3.6-6.3$ years & $1.0[-0.5 ; 2.5]$ & 0.198 & $-1.0[-2.4 ; 0.3]$ & 0.141 \\
\hline $6.4-9.2$ years & $0.2[-1.3 ; 1.8]$ & 0.770 & $-2.8[-4.2 ;-1.4]$ & $<0.001$ \\
\hline$>9.2$ years & $-0.5[-2.1 ; 1.2]$ & 0.578 & $-2.3[-3.8 ;-0.9]$ & 0.001 \\
\hline \multicolumn{5}{|c|}{ Time since discontinuation of TA and/or ddl } \\
\hline$<8.1$ years & Ref & & Ref & \\
\hline $8.1-9.6$ years & $-0.3[-1.8 ; 1.2]$ & 0.702 & $-0.0[-1.4 ; 1.4]$ & 0.965 \\
\hline $9.7-10.7$ years & $1.4[-0.1 ; 2.9]$ & 0.074 & $0.4[-1.1 ; 1.8]$ & 0.593 \\
\hline$>10.7$ & $0.6[-1.0 ; 2.1]$ & 0.460 & $-0.6[-2.0 ; 0.9]$ & 0.431 \\
\hline
\end{tabular}

$\beta$ coefficients represent the degree of change in HU of VAT and SAT, respectively, associated with each level of the explanatory variables

Abbreviations: visceral adipose tissue, VAT; subcutaneous adipose tissue, SAT; thymidine nucleoside analog reverse-transcriptase inhibitors, TA; confidence interval, $\mathrm{Cl}$

All the models were adjusted for age, sex, origin, physical activity, smoking, BMl, cumulative time of exposure to TA and/or ddl, time since discontinuation of TA and/or ddl, VAT area* (or SAT area**)

suggest that adipocytes hypertrophy, rather than hyperplasia, characterizes adipose tissue accumulation in individuals who had been exposed to these treatments. The lack of association between adipose tissue density and time since discontinuation of TA and/or ddI may further suggest irreversible effect of these treatments on adipose tissue density, at least in the time-period considered in the present study.

Mitochondria are fundamental in adipocyte maturation [7]. Mild mitochondrial dysfunction leads to a moderate increase in reactive oxygen species (ROS) production and to reduction in mitochondrial DNA, causing reactive hypertrophy in the affected adipocytes [7]. We speculate that TA and ddI-associated mitochondrial toxicity may lead to mild mitochondria dysfunction in VAT adipocytes, and, consequently, to hypertrophy, that is present years after treatment discontinuation. This hypothesis is in line with previous studies describing longlasting mitochondrial toxicity after TA exposure $[15,16]$. Interestingly, in the SAT compartment, we found prior exposure to TA and/or ddI to be associated with lower adipose tissue density in the presence of smaller SAT area compared to those without exposure. We speculated that in SAT, characterized by lower resistance to mitochondrial toxicity, the same events may lead to severe mitochondrial dysfunction, severe hypertrophy and, eventually, to the loss of adipocytes [7], which may at least partly explain the co-presence of low SAT density and smaller SAT area in PLWH with exposure to TA and/or ddI.

Reduction in adipose tissue density and mitochondrial dysfunction are also associated with reduction of adipocytes' secretory capabilities [6, 17]. Accordingly, in our population we found a direct association between VAT density and plasma adiponectin levels. However, this association was not modified by prior exposure to TA and/or ddI. Low plasma adiponectin is associated with increased systemic inflammation and CVD risk in both uninfected individuals and PLWH [18]. In particular, adiponectin has been previously described to have antioxidant, anti-inflammatory properties and to beneficially affect insulin resistance [19]. In the present study, prior use of TA and/or ddI was associated with excess risk of low plasma adiponectin. While the inverse association between VAT accumulation and adiponectin production is well-known, we present novel data suggesting that prior exposure to TA and/or ddI is associated with significantly reduced adipocyte secretory capabilities even in individuals with comparable visceral fat quantity and years after treatment discontinuation. The interaction between prior exposure to TA and/or ddI with VAT area on adiponectin levels, while only borderline significant, may further suggest a detrimental effect of TA and/or ddI on adipocyte secretory function following adipose tissue accumulation.

Taken together our data suggest the potential irreversibility of harmful effects of TA and/or ddI on adipose tissue function, which may negatively affect CVD risk in PLWH with prior exposure to these treatments. Increasing evidence suggest adipose tissue dysfunction to have a primary role in the development of CVD through both direct and indirect mechanisms [8]. Accordingly, dysfunctional adipocytes have been described to promote systemic inflammation, insulin resistance and atherosclerosis due to, among the others, reduced production of bioactive antioxidant and anti-inflammatory adipokines, such as 
adiponectin [19], and increased production of pro-thrombotic molecules [20] and pro-inflammatory cytokines [8].

The present study has several limitations. Due to the cross-sectional design of the present study, no conclusion on causality can be drawn. Differences in age, sex, and adipose tissue area between the two groups may explain part of the findings. However, a possible confounding effect of these variables was reduced by adjusting for, among the others, age, sex, and adipose tissue area in multivariable analyses. Finally, the lack of histologic samples prevented from investigating the association between cell morphology and CT-findings in the individuals included in the present study and from evaluating the impact of non-adipocyte cell populations on adipose tissue density.

\section{Conclusions}

In conclusion we described excess risk of low adipose tissue density and adiponectin production in PLWH with prior use of TA and/or ddI. These results may suggest that long-lasting adipose tissue dysfunction accompanies alterations in fat distribution, even years after TA and/or ddI discontinuation. Given the central role of adipose tissue in the regulation of metabolism, cell morphology and function analyses may be warranted in order to confirm possible long-lasting detrimental effects of prior TA and ddI exposure on adipose tissue function and, consequently, on cardiometabolic health in PLWH.

\section{Additional file}

Additional file 1: Table S1. Linear Regression Model predicting the degree of change (with 95\% Cl) in HU of VAT and SAT density. (DOCX 14 kb)

\section{Abbreviations}

ddl: didanosine; PLWH: people living with HIV; SAT: subcutaneous adipose tissue; TA: thymidine analogues; VAT: visceral adipose tissue

\section{Acknowledgments}

We thank all the study subjects for their participation. We thank the staff at the Department of Infectious Diseases at Rigshospitalet and at Hvidovre Hospital for their dedicated participation.

\section{Authors' contributions}

$M G$, and SDN conceived of and designed the study. MG and ADK collected data from participating individuals. MG conducted statistical analyses. MG compiled the first draft of the study manuscript and all authors contributed to subsequent revisions. All authors read and approved the final manuscript.

\section{Funding}

This work was supported by Rigshospitalet Research Council, Region Hovedstaden, The Lundbeck Foundation, The Novo Nordisk Foundation, and The Danish National Research Foundation grant 126. The study was designed, conducted, analyzed, and written by the authors without involvement of any commercial party.

Availability of data and materials

All raw data are available by request to corresponding author.

\section{Ethics approval and consent to participate}

Written informed consent was obtained from all participants, and the study was performed in accordance with the ethical guidelines of the 1975 Declaration of Helsinki and approved by the Local Ethical Committee $(\mathrm{H}-$ 15017350) and the Danish Data Protection Agency.

\section{Consent for publication}

Not applicable.

\section{Competing interests}

MG: Travelling grants from Gilead. ADK: Travelling grants from Gilead. JL: No conflicts of interest. KBL: no conflict of interest. AM: Honoraria, lecture fees, and travel support from ViiV and Gilead. BL: No conflict of interest. KFK: No conflict of interests. SDN: Unrestricted research grants from Novo Nordisk Foundation, Lundbeck Foundation, Augustinus Foundation, Rigshospitalet Research Council. Travelling grants from Gilead and GSKNiiV. Advisory board activity for Gilead and GSKN ViiV.

\section{Author details}

${ }^{1}$ Viro-immunology Research Unit, Department of Infectious Diseases 8632, Rigshospitalet - University of Copenhagen, Blegdamsvej 9B, DK-2100 Copenhagen $\varnothing$, Denmark. ${ }^{2} \mathrm{HIV}$ Epidemiology and Biostatistics Unit, Department of Infection and Population Health, UCL, London, UK. ${ }^{3}$ Center for inflammation and Metabolism, Rigshospitalet, Copenhagen, Denmark. ${ }^{4}$ Department of pulmonary and infectious diseases, Nordsjællands Hospital, Hillerød, Denmark. ${ }^{5} \mathrm{CHIP}$, Department of Infectious Diseases 8632, Rigshospitalet, University of Copenhagen, Copenhagen, Denmark.

${ }^{6}$ Department of Cardiology, Rigshospitalet, University of Copenhagen, Copenhagen, Denmark. 'Department of Radiology, Rigshospitalet, University of Copenhagen, Copenhagen, Denmark.

Received: 29 May 2019 Accepted: 31 July 2019

Published online: 09 August 2019

\section{References}

1. Gelpi M, Afzal S, Fuchs A, Lundgren J, Knudsen AD, Drivsholm N, et al. Prior exposure to thymidine analogues and didanosine is associated with longlasting alterations in adipose tissue distribution and cardiovascular risk factors. AIDS [Internet]. 2018 Dec 21; Available from: http://www.ncbi.nlm. nih.gov/pubmed/30585844

2. Lee JJ, Pedley A, Hoffmann U, Massaro JM, Fox CS. Association of Changes in abdominal fat quantity and quality with incident cardiovascular disease risk factors. J Am Coll Cardiol [Internet]. 2016;68(14):1509-21. Available from: http://www.ncbi.nlm.nih.gov/pubmed/27687192

3. Rosenquist KJ, Pedley A, Massaro JM, Therkelsen KE, Murabito JM, Hoffmann $\mathrm{U}$, et al. Visceral and subcutaneous fat quality and cardiometabolic risk. JACC Cardiovasc Imaging [Internet]. 2013;6(7):762-71. Available from: http:// www.ncbi.nlm.nih.gov/pubmed/23664720

4. Lee JJ, Pedley A, Hoffmann U, Massaro JM, Keaney JF, Vasan RS, et al. Crosssectional associations of computed tomography (CT)-derived adipose tissue density and Adipokines: the Framingham heart study. J Am Heart Assoc [Internet] 2016;5(3):e002545. Available from: http://www.ncbinlm.nih.gov/ pubmed/26927600.

5. Abraham TM, Pedley A, Massaro JM, Hoffmann U, Fox CS. Association between visceral and subcutaneous adipose depots and incident cardiovascular disease risk factors. Circulation [Internet]. 2015;132(17):163947. Available from: http://www.ncbi.nlm.nih.gov/pubmed/26294660

6. Murphy RA, Register TC, Shively CA, Carr JJ, Ge Y, Heilbrun ME, et al. Adipose tissue density, a novel biomarker predicting mortality risk in older adults. J Gerontol A Biol Sci Med Sci [Internet]. 2014;69(1):109-17. Available from: http://www.ncbi.nlm.nih.gov/pubmed/23707956

7. Caron-Debarle M, Lagathu C, Boccara F, Vigouroux C, Capeau J. HIVassociated lipodystrophy: from fat injury to premature aging. Trends Mol Med [Internet]. 2010;16(5):218-29. Available from: http://www.ncbi.nlm.nih. gov/pubmed/20400373

8. Oikonomou EK, Antoniades C. The role of adipose tissue in cardiovascular health and disease. Nat Rev Cardiol [Internet]. 2019;16(2):83-99. Available from: http://www.ncbi.nlm.nih.gov/pubmed/30287946

9. Grant RW, Dixit VD. Adipose tissue as an immunological organ. Obesity (Silver Spring)) [Internet]. 2015;23(3):512-8. Available from: http://www.ncbi. nlm.nih.gov/pubmed/25612251 
10. Ronit A, Haissman J, Kirkegaard-Klitbo DM, Kristensen TS, Lebech A-M, Benfield T, et al. Copenhagen comorbidity in HIV infection (COCOMO) study: a study protocol for a longitudinal, non-interventional assessment of non-AIDS comorbidity in HIV infection in Denmark. BMC Infect Dis [Internet]. 2016;16(1):713. Available from: http://bmcinfectdis.biomedcentral. com/articles/10.1186/s12879-016-2026-9

11. Martin A, Smith DE, Carr A, Ringland C, Amin J, Emery S, et al. Reversibility of lipoatrophy in HIV-infected patients 2 years after switching from a thymidine analogue to abacavir: the MITOX extension study. AIDS [Internet] 2004;18(7):1029-36. Available from: http://www.ncbi.nlm.nih.gov/ pubmed/15096806

12. The EACS Executive Committee. European guidelines for the clinical management and treatment of HIV infected adults. 2005;(1):4. Available from: http://www.eacsociety.org/guidelines/guidelines-archive/archive.html

13. Gelpi M, Afzal S, Lundgren J, Ronit A, Roen A, Mocroft A, et al. Higher risk of abdominal obesity, elevated LDL cholesterol and hypertriglyceridemia, but not of hypertension, in people living with HIV: results from the Copenhagen comorbidity in HIV infection (COCOMO) study. Clin Infect Dis [Internet] 2018; Available from: http://www.ncbi.nlm.nih.gov/pubmed/29471519.

14. Côté JA, Nazare J-A, Nadeau M, Leboeuf M, Blackburn L, Després J-P, et al. Computed tomography-measured adipose tissue attenuation and area both predict adipocyte size and cardiometabolic risk in women. Adipocyte [Internet]. 2015;5(1):35-42. Available from: http://www.ncbi.nlm.nih.gov/ pubmed/27144095

15. García-Otero L, López M, Guitart-Mampel M, Morén C, Goncé A, Esteve C, et al. Cardiac and mitochondrial function in HIV-uninfected fetuses exposed to antiretroviral treatment. PLoS One [Internet]. 2019;14(3):e0213279. Available from: http://www.ncbi.nlm.nih.gov/pubmed/30830946

16. Poirier MC, Divi RL, Al-Harthi L, Olivero OA, Nguyen V, Walker B, et al. Longterm mitochondrial toxicity in HIV-uninfected infants born to HIV-infected mothers. J Acquir Immune Defic Syndr [Internet]. 2003;33(2):175-83. Available from: http://www.ncbi.nlm.nih.gov/pubmed/12794551

17. Koh EH, Park J-Y, Park H-S, Jeon MJ, Ryu JW, Kim M, et al. Essential role of mitochondrial function in adiponectin synthesis in adipocytes. Diabetes [Internet]. 2007;56(12):2973-81. Available from: http://www.ncbi.nlm.nih.gov/ pubmed/17827403

18. Tsiodras S, Mantzoros C. Leptin and adiponectin in the HIV associated metabolic syndrome: physiologic and therapeutic implications. Am J Infect Dis [Internet]. 2006;2(3):141-52. Available from: http://www.ncbi.nlm.nih.gov/ pubmed/17183414

19. Margaritis M, Antonopoulos AS, Digby J, Lee R, Reilly S, Coutinho P, et al. Interactions between vascular wall and perivascular adipose tissue reveal novel roles for adiponectin in the regulation of endothelial nitric oxide synthase function in human vessels. Circulation [Internet]. 2013;127(22): 2209-21. Available from: http://www.ncbi.nlm.nih.gov/pubmed/23625959

20. Vilahur G, Ben-Aicha S, Badimon L. New insights into the role of adipose tissue in thrombosis. Cardiovasc Res [Internet]. 2017;113(9):1046-54. Available from: http://www.ncbi.nlm.nih.gov/pubmed/28472252

\section{Publisher's Note}

Springer Nature remains neutral with regard to jurisdictional claims in published maps and institutional affiliations.

Ready to submit your research? Choose BMC and benefit from:
- fast, convenient online submission
- thorough peer review by experienced researchers in your field
- rapid publication on acceptance
- support for research data, including large and complex data types
- gold Open Access which fosters wider collaboration and increased citations
- maximum visibility for your research: over 100M website views per year
At BMC, research is always in progress.
Learn more biomedcentral.com/submissions

